\title{
Urine albumin dipstick independently predicts cardiovascular and renal outcomes among rural Thai population: a 14-year retrospective cohort study
}

Noppawit Aiumtrakul ${ }^{1 *}$, Kitinan Phichedwanichskul ${ }^{1}$, Surapong Saravutthikul ${ }^{1}$, Kamonwan Ottasat ${ }^{1}$, Kesinee Visuthitepkul', Thitinat Jaruthiti ${ }^{1}$, Sarita Jinawong ${ }^{1}$, Kwanchanok Chanthowong ${ }^{1}$, Varot Pengsritong ${ }^{1}$, Nattawinee Horadee', Chotip Jitudomtham ${ }^{1}$, Torpathom Pruekprasert', Thakorn Tawatkiratipol', Tunjira Chokjutha', Panuwat Pongpripoom', Chirayu Wiwatwarapon', Pirawich Sriyarun ${ }^{1}$, Natcha Homrossukhon?', Annop Kittithaworn ${ }^{1}$, Wisit Kaewput ${ }^{1}$, Ram Rangsin ${ }^{1}$ and Bancha Satirapoj ${ }^{2}$

\begin{abstract}
Background: Albuminuria is an established risk marker for both cardiovascular and renal outcomes. In this study, we expected to use portable and inexpensive test strips to detect urine albumin level for risk stratification in cardiovascular and renal outcomes among rural Thai community.

Objective: To evaluate the relationship between urine albumin dipstick and cardiovascular and renal complications in rural Thai population.

Methods: We conducted a retrospective study in 635 rural Thai adults who tested urine albuminuria by using commercial urine albumin dipstick and the Micral-albumin test II strips at baseline. The subjects were divided into normoalbuminuria (albumin $<20 \mathrm{mg} / \mathrm{L}$ ), microalbuminuria (albumin 20-200 mg/L), or macroalbuminuria (Urine dipstick at least $1+$ or albumin $>200 \mathrm{mg} / \mathrm{L}$ ). We collected data on the incidences of primary composite outcomes including cardiovascular or renal morbidity and mortality. Incident density and cox regression were analyzed to evaluate the association between albuminuria status and primary composite outcome.

(Continued on next page)
\end{abstract}

\footnotetext{
* Correspondence: tan.niie@me.com

1 Department of Military and Community Medicine, Phramongkutklao College of Medicine, Bangkok, Thailand

Full list of author information is available at the end of the article
}

(c) The Author(s). 2021 Open Access This article is licensed under a Creative Commons Attribution 4.0 International License, which permits use, sharing, adaptation, distribution and reproduction in any medium or format, as long as you give appropriate credit to the original author(s) and the source, provide a link to the Creative Commons licence, and indicate if changes were made. The images or other third party material in this article are included in the article's Creative Commons licence, unless indicated otherwise in a credit line to the material. If material is not included in the article's Creative Commons licence and your intended use is not permitted by statutory regulation or exceeds the permitted use, you will need to obtain permission directly from the copyright holder. To view a copy of this licence, visit http://creativecommons.org/licenses/by/4.0/ The Creative Commons Public Domain Dedication waiver (http://creativecommons.org/publicdomain/zero/1.0/) applies to the data made available in this article, unless otherwise stated in a credit line to the data. 
(Continued from previous page)

Results: During an average 14-year follow-up, 102 primary composite events occurred including 59 (13.1\%), 32 (20.6\%) and 11 (39.3\%) among 452, 155, and 28 subjects with normoalbuminuria, microalbuminuria, and macroalbuminuria, respectively. Incident densities of primary composite outcome were elevated continually according to the degree of albuminuria (9.36, 17.11 and 38.12 per 1000 person-years). Compared with the subjects without albuminuria, subjects with microalbuminuria and macroalbuminuria at baseline had higher risk for primary composite outcome in univariate model. After multivariate analysis was performed, the effect of macroalbuminuria was only persisted with 3.13-fold risk (adjusted HR 3.13; 95\% Cl 1.40-6.96, $P=0.005$ ).

Conclusion: Albuminuria from semi-quantitative methods is an important factor predicting cardiovascular and renal risk among subjects in Thai rural population. Our findings support to also incorporating urine albumin dipstick into assessments of cardiovascular risk in the general population.

Keywords: Microalbuminuria, Cardiovascular outcomes, Chronic kidney disease

\section{Introduction}

The presence of urine albumin reflects endothelial and vascular damage [1]. Albuminuria is an established risk marker for both cardiovascular and renal outcomes [2-9] not only in diabetes patients $[10,11]$ but also in hypertension $[12,13]$ and in the general population $[14,15]$. Some studies also showed microalbuminuria as an independent predictor for cardiovascular and all-cause mortality [14, 16]. In developed countries, independent association between dipstick proteinuria and an increase in cardiovascular morbidity or all-cause mortality among adult were demonstrated in several studies [17-21]. However, there are limited data about proteinuria and its cardiovascular outcome in developing country [22] where the costeffective screening test should be performed, especially in primary care setting. In this study, we expected to use portable and inexpensive test strips to detect urine albumin level for risk stratification in cardiovascular and renal outcomes among rural Thai community.

\section{Materials and methods Subjects}

A retrospective cohort study was conducted in 755 rural Thai population aged 35 years and older at Moo 15 Baan Nayao Thakadan Subdistrict, Sanamchaikhet District, Chacherngsao Province, Thailand since Febuary 2004. The study protocol was approved by the Institutional Review Board of Royal Thai Army Medical Department's committee on human research, and written informed consent was obtained from all subjects. Exclusion criteria are pregnancy, having menstrual period, urinary tract infection, pyuria, nephrolithiasis, hematuria, history of coronary artery disease (CAD), history of stroke, endstage renal disease (ESRD) and subjects who were unable to collect first-spot morning urine or did not have information on dipstick proteinuria. Therefore, 635 subjects were enrolled which consisted of 452, 155 and 28 individuals in Normoalbuminuria, Microalbuminuria and Macroalbuminuria group, respectively (Fig. 1). To study the effect of albuminuria on cardiovascular outcomes, especially mortality, a study by Valmadrid et al. in 2000 was referred [23]. Sample size needed 142, 71 and 36 individuals in Normoalbuminuria, Microalbuminuria and Macroalbuminuria group, respectively.

\section{Data collection}

At baseline, demographic data were obtained using standardized questionnaire including age, gender, weight, height, blood pressure, history of smoking, diabetes, hypertension dyslipidemia and current medication. According to the Seventh Report of the Joint National Committee on Prevention, Detection, Evaluation, and Treatment of High Blood Pressure (JNC 7), hypertensive subjects were defined by office blood pressure measurement with systolic $\geq 140 \mathrm{mmHg}$ or diastolic $\geq 90 \mathrm{mmHg}$. For medication, ACEI/ARBs included enalapril and losartan, sulfonylurea included glipizide and glibenclamide, beta-blockers included atenolol, propranolol and metoprolol and diuretics included hydrochlorothiazide, furosemide and spinorolactone. These agents were all available medication in primary care centers around the rural community. First-morning spot urine and venipuncture were done for urine dipstick and serum creatinine testing respectively. All urine samples were examined by Micral test to stratify urine albumin group. Subjects who had urine microalbumin less than $20 \mathrm{mg} / \mathrm{L}$ defined as "Normoalbuminuria", for those who had Micral test equal to or over than $20 \mathrm{mg} / \mathrm{L}$ will be continually tested by Combur UX urine dipstick. If the samples had urine microalbumin equal to or less than $200 \mathrm{mg} /$ $\mathrm{L}$, the subjects would be defined as "Microalbuminuria", for those who had over $200 \mathrm{mg} / \mathrm{L}$, they would be defined as "Macroalbuminuria" group. Serum creatinine was tested by enzymatic method. eGFR (in $\mathrm{ml} / \mathrm{min}$ per $1.73 \mathrm{~m} 2$ ) was calculated using the Chronic Kidney Disease Epidemiology Collaboration (CKDEPI) [24]. 


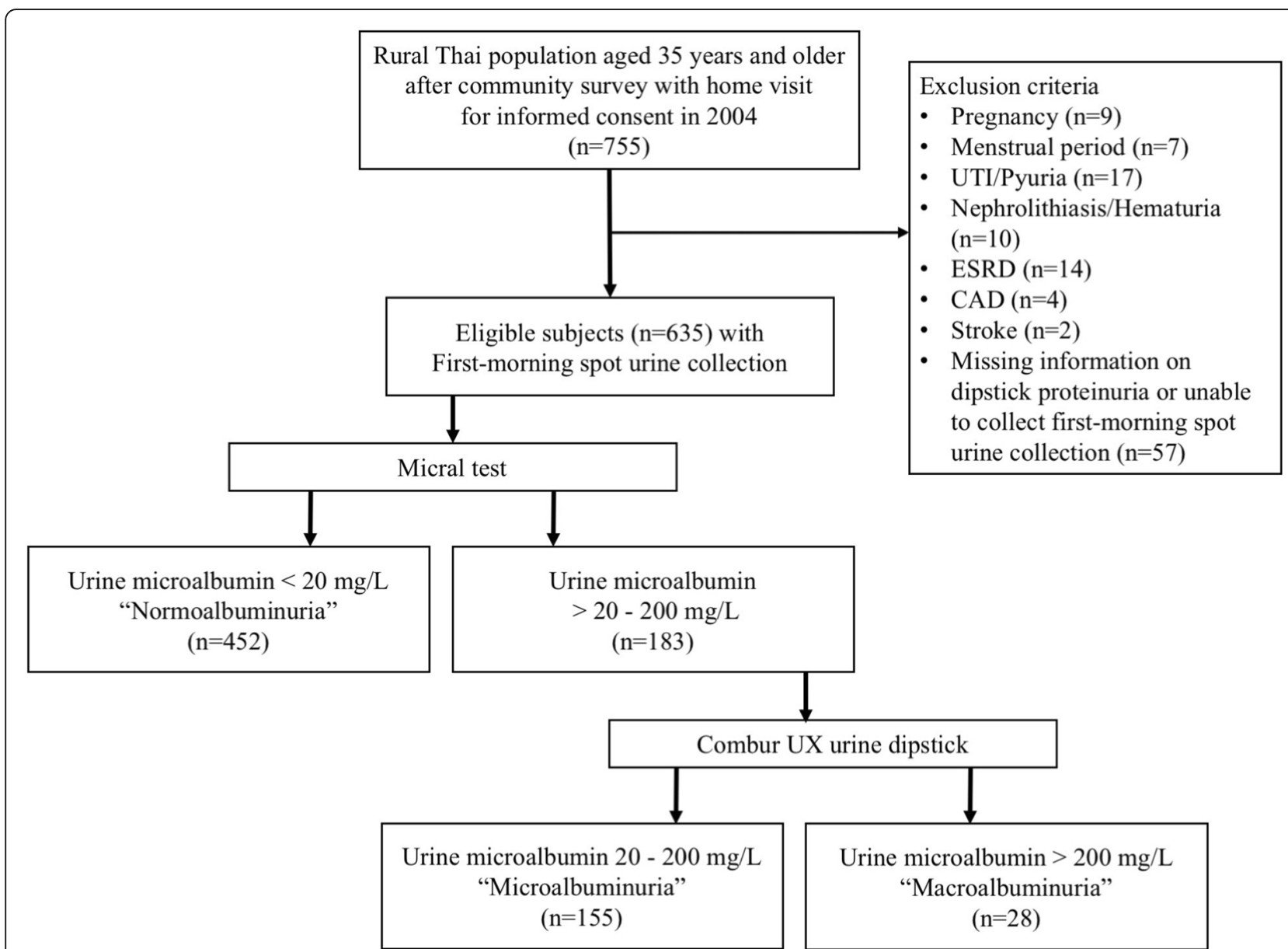

Fig. 1 Enrollment flowchart. UTI Urinary tract infection, ESRD End-stage renal disease, CAD Coronary artery disease

In December 2017, information about cardiovascular events, renal events and all-cause mortality were collected from electronic medical record (EMR) in primary care hospitals nearby, district office and home visit.

\section{Outcome definition}

Primary composite outcome of the study consists of cardiovascular or renal morbidity and mortality. Secondary composite outcome consists of cardiovascular or renal morbidity and all-cause mortality. International Classification of Diseases 10 (ICD-10) codes were identified in the hospital database to collect the outcome from EMR. Cardiovascular event was defined as ICD-I00 to ICD-I52 or ICD-I60 to ICD-I69. Renal event was defined as ICDN00 to N19 or eGFR lower than $15 \mathrm{~mL} / \mathrm{min} / 1.73 \mathrm{~m} 2$ or initiation of renal replacement therapy. Information of mortality was obtained from EMR, district office and home visit. The duration between the baseline date and date of first event in each individual was the calculated follow-up time.

\section{Statistical analysis}

Data were analyzed using IBM SPSS 22.0 (SPSS, Chicago, IL, USA). Baseline characteristics of subjects were analyzed using descriptive statistics. Categorical data were presented as number with percentage while continuous data were presented as means with standard deviation. ANOVA test was used to compare continuous variables and Chi-square test was used for categorical variables among albuminuria groups. Incident density was calculated and reported as the number of events per 1000 person-years for both primary and secondary composite outcomes Kaplan-Meier analysis and log-rank test were used for both of the composite outcomes. Cox proportional hazard model for multivariate analysis, adjusting for age, gender, type 2 diabetes, hypertension, eGFR, aspirin, ACEI/ARBs, insulin and metformin at baseline, on both of the composite outcomes was calculated and reported as hazard ratio (HR) with $95 \%$ confidence intervals $(\mathrm{CI})$, involving survival time to the first event of any subjects. $P$-values were two-sided and statistical significance was indicated for $p$-value $<0.05$. 


\section{Results}

We identified 452, 155, and 28 subjects with normoalbuminuria, microalbuminuria and macroalbuminuria, respectively. The subjects in each group had similar characteristic in age, gender, smokers, dyslipidemia patient and the use of beta-blockers, amlodipine, diuretics, sulfonylurea, metformin, simvastatin and gemfibrozil. BMI, blood pressure, hypertensive patient, diabetic patient and the use of ACEI/ARBs, insulin and aspirin were different with higher value as higher level of albuminuria group, except serum creatinine that lower among microalbuminuria than normoalbuminuria group (Table 1).

The frequency of clinical outcomes and the incident densities of both composite outcomes were increased consecutively according to the degree of albuminuria (Tables 2, 3 and 4).

Univariate analysis of cox regression model in primary composite outcome, compared with the subjects without albuminuria, subjects with microalbuminuria and macroalbuminuria at baseline had a 1.82-fold and 4.09-fold respectively higher risk for cardiovascular or renal morbidity and mortality (unadjusted HR 1.82; 95\% CI 1.15-2.89, $P=$
0.011 and unadjusted HR 4.09; 95\% CI 2.21-7.88, $P=<$ 0.001 ). Significant associations were also found in age, gender, type 2 diabetes, hypertension, serum creatinine, eGFR and the use of aspirin, ACEI/ARBs, insulin and metformin as well. In multivariate model, macroalbuminuria, hypertension and aspirin were still significant with 3.13fold, 2.6-fold and 5.28-fold higher risk respectively (adjusted HR 3.13; 95\% CI 1.4-6.96, $P=0.005$, adjusted HR 2.6; 95\% CI 1.35-5.0, $P=0.004$ and adjusted HR 5.28; $95 \%$ CI 2.75-10.14), whereas, metformin significantly reduced risk for 0.29- fold (adjusted HR 3.31; 95\% CI 0.09-0.94) after adjusting for age, gender, type 2 diabetes, hypertension, eGFR, aspirin, ACEI/ARBs, insulin and metformin, (Table 5).

For secondary composite outcome, univariate cox regression analysis revealed similar trend and significant variables as the previous model, except microalbuminuria. Multivariate analysis with the same adjusting factors showed that age, hypertension and aspirin were significantly associated with the outcome with 1.05-fold, 1.9-fold and 2.08-fold risk respectively. (adjusted HR 1.05; 95\% CI 1.02-1.07, $P=<0.001$, adjusted HR 1.9; 95\% CI 1.16-3.11, $P=0.011$ and adjusted HR 2.08; 95\%

Table 1 Baseline characteristics

\begin{tabular}{|c|c|c|c|c|}
\hline & \multicolumn{3}{|l|}{ Urine albumin status } & \multirow{2}{*}{$\begin{array}{l}P \text { - } \\
\text { value }\end{array}$} \\
\hline & Normoalbuminuria $(n=452)$ & Microalbuminuria $(n=155)$ & Macroalbuminuria $(n=28)$ & \\
\hline Age (years) & $50.48 \pm 11.45$ & $51.06 \pm 11.31$ & $53.57 \pm 12.46$ & 0.359 \\
\hline Male (\%) & $197(43.6 \%)$ & $70(45.2 \%)$ & $12(42.9 \%)$ & 0.937 \\
\hline $\mathrm{BMI}\left(\mathrm{kg} / \mathrm{m}^{2}\right)$ & $23.54 \pm 3.91$ & $24.42 \pm 3.93$ & $25.88 \pm 4.61$ & 0.016 \\
\hline Systolic BP (mmHg) & $121.2 \pm 16.45$ & $122.49 \pm 16.71$ & $129.38 \pm 21.48$ & 0.048 \\
\hline Diastolic BP (mmHg) & $77.5 \pm 9.19$ & $79.58 \pm 10.29$ & $83.46 \pm 13.27$ & 0.002 \\
\hline History of Hypertension & $112(24.8 \%)$ & $50(32.3 \%)$ & $14(50 \%)$ & 0.005 \\
\hline History of Type2 DM & $38(8.4 \%)$ & $21(13.5 \%)$ & $7(25 \%)$ & 0.007 \\
\hline History of Dyslipidemia & $39(8.6 \%)$ & $10(6.5 \%)$ & $4(14.3 \%)$ & 0.356 \\
\hline History of smoking (\%) & 87 (19.2\%) & 37 (23.9\%) & $4(14.3 \%)$ & 0.340 \\
\hline Serum creatinine (mg/dL) & $0.71 \pm 0.19$ & $0.68 \pm 0.14$ & $0.95 \pm 0.48$ & $<0.001$ \\
\hline eGFR (ml/min/1.73m²) & $91.69 \pm 18.85$ & $93.28 \pm 16.7$ & $78.8 \pm 26.21$ & 0.026 \\
\hline Aspirin (use) & $28(6.2 \%)$ & $21(13.5 \%)$ & $4(14.3 \%)$ & 0.009 \\
\hline ACEl/ARBs (use) & $45(10 \%)$ & $31(20 \%)$ & $6(21.4 \%)$ & 0.002 \\
\hline Beta-Blockers (use) & $24(5.3 \%)$ & $9(5.8 \%)$ & $1(3.6 \%)$ & 0.887 \\
\hline Amlodipine (use) & $29(6.4 \%)$ & $15(9.7 \%)$ & $3(10.7 \%)$ & 0.323 \\
\hline Diuretics (use) & 46 (10.2\%) & $16(10.3 \%)$ & $5(17.9 \%)$ & 0.436 \\
\hline Insulin (use) & $7(1.5 \%)$ & $7(4.5 \%)$ & $2(7.1 \%)$ & 0.035 \\
\hline Metformin (use) & $30(6.6 \%)$ & $18(11.6 \%)$ & $4(14.3 \%)$ & 0.072 \\
\hline Sulfonylurea (use) & $21(4.6 \%)$ & $13(8.4 \%)$ & $2(7.1 \%)$ & 0.208 \\
\hline Simvastatin (use) & $45(10 \%)$ & $15(9.7 \%)$ & $3(10.7 \%)$ & 0.985 \\
\hline Gemfibrozil (use) & $13(2.9 \%)$ & $5(3.2 \%)$ & $2(7.1 \%)$ & 0.454 \\
\hline
\end{tabular}

Data presents as mean \pm SD and number with percentage

$B M I$ Body mass index, BP Blood pressure, DM Diabetes mellitus, eGFR Estimated glomerular filtration rate, ACEI/ARBs Angiotensin-converting enzyme inhibitors/ angiotensin II receptor blockers. All variables are at baseline level 
Table 2 Clinical outcomes according to urine albumin status

\begin{tabular}{|c|c|c|c|c|}
\hline & \multicolumn{3}{|l|}{ Urine albumin status } & \multirow{2}{*}{$\begin{array}{l}P \text { - } \\
\text { value }\end{array}$} \\
\hline & Normoalbuminuria & Microalbuminuria & Macroalbuminuria & \\
\hline Primary Composite Outcomes & $59(13.1 \%)$ & $32(20.6 \%)$ & $11(39.3 \%)$ & $\begin{array}{l}< \\
0.001\end{array}$ \\
\hline $\begin{array}{l}\text { Cardiovascular events (ischemic heart disease, HF, PVD, stroke and } \\
\text { cardiovascular death) }\end{array}$ & $48(10.6 \%)$ & $22(14.2 \%)$ & $7(25 \%)$ & 0.051 \\
\hline Renal events (ESRD, dialysis and renal death) & $19(4.2 \%)$ & $8(5.2 \%)$ & $7(25 \%)$ & $\begin{array}{l}< \\
0.001\end{array}$ \\
\hline Overall mortality & $70(15.5 \%)$ & $22(14.2 \%)$ & $8(28.6 \%)$ & 0.151 \\
\hline
\end{tabular}

Primary composite outcome includes cardiovascular or renal morbidity and mortality. International Classification of Diseases 10 (ICD-10) codes were identified in the hospital database to collect the outcome from EMR. Cardiovascular event was defined as ICD-I00 to ICD-I52 or ICD-I60 to ICD-I69. Renal event was defined as ICD-N00 to N19 or eGFR lower than $15 \mathrm{~mL} / \mathrm{min} / 1.73 \mathrm{~m} 2$ or initiation of renal replacement therapy HF Heart failure, PVD Peripheral vascular disease, ESRD End-stage renal disease

CI 1.2-3.6, $P=0.009)$ However, macroalbuminuria with 1.92-fold risk might be counted as "clinically" significant factor in multivariate model (adjusted HR 1.92; 95\% CI 0.9-4.08, $P=<0.09$ ) (Table 6).

Kaplan-Meier analysis illustrates the consecutively lower survival rate according to higher level of albuminuria for both composite outcomes, with the prominent effect among macroalbuminuria group (log-rank test, $P=$ $<0.001$, Fig. 2a and log-rank test, $P=0.017$, Fig. 2b).

\section{Discussion}

The 14-year retrospective cohort study showed that urine albumin related to cardiovascular, renal and mortality outcomes. Although, there were other cardiovascular risk factors at baseline, macroalbuminuria still manifested the independent association of cardiovascular and renal complications in primary composite outcome when compared with normoalbuminuria and microalbuminuria.

Results from clinical outcomes, incident density and Kaplan-Meier curve were consistent with previous studies which conducted in diabetic setting. The higher degree of albuminuria had a significant association with higher cardiovascular [23], renal [25] and all-cause mortality [23, 25]. Microalbuminuria had a slightly significant association to the outcome compared with normal urine albumin group while gross albuminuria group had a profound risk.

In this study, multivariate analysis of cox regression model for both composite outcomes did not show microalbuminuria as an independent risk factor. Some prior studies, mostly in diabetes, found that microalbuminuria was not independent risk of cardiovascular [26-31] and mortality [32] outcome as well. On the other hand, significant associations between microalbuminuria and cardiovascular morbidity or mortality [8, $23,28,33$ and also total mortality [34-44] were reported. For renal outcome, a study by Berhane et al. [25] reported significant association with 2.1 times adjusted hazard ratio (HR) between end-stage renal disease (ESRD) and microalbuminuria when compared with normoalbuminuria. However, most of these studies' population were diabetic.

Our findings revealed that macroalbuminuria had 3.13fold higher risk than normoalbuminuria for cardiovascular or renal morbidity and mortality (adjusted HR 3.13; 95\% CI $1.4-6.96, P=0.005)$. It is likely that macroalbuminuria was associated with secondary composite outcome which included all-cause mortality (adjusted HR 1.92; 95\% CI $0.9-4.08, P=0.09)$. Prior studies showed either significant $[42,45-47]$ or no $[27,33,40]$ association between macroalbuminuria and cardiovascular mortality. Whereas, a number of studies found the association between macroalbuminuria and all-cause mortality [34, 36, 37, 43, 48-53]. For renal outcome, several landmark studies discovered albuminuria as risk of ESRD [54-57]. especially macroalbuminuria that had 9.3 times higher of ESRD incidence than normoalbuminuria [25].

Aging, hypertension, aspirin and metformin also revealed the independent relationship to the outcomes. Increased age definitely associated with prevalence and progression of non-communicable disease [58-60], cardiovascular event [61-63] and mortality [64].

Table 3 Incident density of primary composite outcome (/1000 person-years)

\begin{tabular}{lllll}
\hline Primary composite outcome & Person-year (year) & Primary composite outcome (n) & Incident density (/1000 person-years) & 95\% Cl \\
\hline Normoalbuminuria & 5127.92 & 48 & 9.36 & $7.05-12.42$ \\
Microalbuminuria & 1695.25 & 29 & 17.11 & $11.89-24.62$ \\
Macroalbuminuria & 288.58 & 11 & 38.12 & $21.11-68.83$ \\
Total & $\mathbf{7 1 1 1 . 7 5}$ & $\mathbf{8 8}$ & $\mathbf{1 2 . 3 7}$ & $\mathbf{1 0 . 0 4 - 1 5 . 2 5}$
\end{tabular}

Primary composite outcome includes cardiovascular or renal morbidity and mortality 
Table 4 Incident density of secondary composite outcome (/1000 person-years)

\begin{tabular}{llllr}
\hline Secondary composite outcome & Person-year (year) & Secondary composite outcome $(\mathbf{n})$ & \multicolumn{2}{l}{$\begin{array}{l}\text { Incident density } \\
\text { (/1000 person-years) }\end{array}$} \\
\hline Normoalbuminuria & 5269 & 109 & 20.69 & $\mathbf{9 5 \% ~ C l}$ \\
Microalbuminuria & 1733.50 & 43 & 24.81 & $17.15-24.96$ \\
Macroalbuminuria & 288.58 & 13 & 45.05 & $26.16-77.58$ \\
Total & $\mathbf{7 2 9 1 . 0 8}$ & $\mathbf{1 6 5}$ & $\mathbf{2 2 . 6 3}$ & $\mathbf{1 9 . 4 3 - 2 6 . 3 6}$
\end{tabular}

Secondary composite outcome includes cardiovascular or renal morbidity and all-cause mortality

Hypertension and diabetes are established risk factors in cardiovascular and renal diseases $[65,66]$. We had high proportion of hypertensive subjects at baseline that possibly have an impact on the outcome. Besides, small proportion of type 2 diabetes at baseline could explain why it did not have significant risk to the outcomes. Even though this study does not have baseline fasting plasma glucose, hemoglobinA1c or duration of diabetes to indicate the severity of disease, small amount of insulin use could roughly tell that overall subjects were not poorly controlled diabetes. Therefore, effect of hyperglycemia might not participate much in the outcome's pathogenesis.
Aspirin had highest magnitude of association in both composite outcomes (adjusted HR 5.28; 95\% CI 2.7510.14) (adjusted HR 2.08; 95\% CI 1.2-3.6, $P=0.009$ ). Although aspirin is a protective medication for cardiovascular complication [67], this result could be explained by the individuals who took aspirin either for primary or secondary prevention at baseline reflects to their own high cardiovascular risk compared to the person who did not. Furthermore, drug compliance was not assessed in this study which poor compliance is common among patient receiving low-dose aspirin [68].

Some studies suggested that metformin could have benefit in cardiovascular morbidity and mortality [69].

Table 5 Univariate and multivariate of primary composite outcome

\begin{tabular}{|c|c|c|c|c|}
\hline \multirow[t]{2}{*}{ Baseline variables } & \multicolumn{2}{|l|}{ Univariate } & \multicolumn{2}{|l|}{ Multivariate } \\
\hline & Crude HR $(95 \% \mathrm{Cl})$ & $p$-value & Adjusted $\mathrm{HR}^{\mathrm{a}}(95 \% \mathrm{Cl})$ & $p$-value \\
\hline Normoalbuminuria & Reference & 1 & Reference & 1 \\
\hline Microalbuminuria & $1.82(1.15,2.89)$ & 0.011 & $1.4(0.8,2.44)$ & 0.235 \\
\hline Macroalbuminuria & $4.09(2.12,7.88)$ & $<0.001$ & $3.13(1.4,6.96)$ & 0.005 \\
\hline Age (years) & $1.04(1.02,1.05)$ & $<0.001$ & $1.02(1,1.05)$ & 0.084 \\
\hline Male (\%) & $1.55(1.02,2.36)$ & 0.04 & $1.26(0.74,2.15)$ & 0.397 \\
\hline $\mathrm{BMI}\left(\mathrm{kg} / \mathrm{m}^{2}\right)$ & $1.02(0.96,1.08)$ & 0.498 & & \\
\hline Systolic BP (mmHg) & $1.01(0.99,1.02)$ & 0.266 & & \\
\hline Diastolic BP (mmHg) & $1(0.98,1.02)$ & 0.867 & & \\
\hline History of Hypertension & $3.26(2.14,4.95)$ & $<0.001$ & $2.6(1.35,5)$ & 0.004 \\
\hline History of Type2 DM & $3.18(1.95,5.19)$ & $<0.001$ & $1.64(0.48,5.66)$ & 0.43 \\
\hline History of Dyslipidemia & $1.6(0.85,3.02)$ & 0.143 & & \\
\hline History of smoking (\%) & $1.33(0.82,2.16)$ & 0.249 & & \\
\hline Serum creatinine (mg/dL) & $3.85(1.53,9.68)$ & 0.004 & & \\
\hline eGFR $\left(\mathrm{ml} / \mathrm{min} / 1.73 \mathrm{~m}^{2}\right)$ & $0.98(0.97,0.99)$ & $<0.001$ & $0.99(0.98,1.01)$ & 0.365 \\
\hline Aspirin (use) & $6.73(4.33,10.49)$ & $<0.001$ & $5.28(2.75,10.14)$ & $<0.001$ \\
\hline ACEI/ARBs (use) & $2.86(1.79,4.57)$ & $<0.001$ & $0.64(0.32,1.27)$ & 0.204 \\
\hline Insulin (use) & $5.67(2.84,11.31)$ & $<0.001$ & $1.19(0.42,3.4)$ & 0.738 \\
\hline Metformin (use) & $2.41(1.36,4.28)$ & 0.003 & $0.29(0.09,0.94)$ & 0.038 \\
\hline
\end{tabular}

Primary composite outcome includes cardiovascular or renal morbidity and mortality

$B M I$ Body mass index, BP Blood pressure, DM Diabetes mellitus, eGFR Estimated glomerular filtration rate, ACEI/ARBs Angiotensin-converting enzyme inhibitors/ angiotensin II receptor blockers. All variables are at baseline level

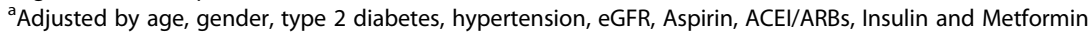


Table 6 Univariate and multivariate of secondary composite outcome

\begin{tabular}{|c|c|c|c|c|}
\hline \multirow[t]{2}{*}{ Baseline variables } & \multicolumn{2}{|l|}{ Univariate } & \multicolumn{2}{|l|}{ Multivariate } \\
\hline & Crude HR (95\%Cl) & $\overline{p \text {-value }}$ & Adjusted HR ${ }^{\mathrm{a}}(95 \% \mathrm{Cl})$ & $p$-value \\
\hline Normoalbuminuria & Reference & 1 & Reference & 1 \\
\hline Microalbuminuria & $1.2(0.84,1.71)$ & 0.312 & $1.14(0.75,1.73)$ & 0.549 \\
\hline Macroalbuminuria & $2.23(1.26,3.97)$ & 0.006 & $1.92(0.9,4.08)$ & 0.09 \\
\hline Age (years) & $1.04(1.03,1.06)$ & $<0.001$ & $1.05(1.02,1.07)$ & $<0.001$ \\
\hline Male (\%) & $1.45(1.07,1.97)$ & 0.016 & $1.21(0.82,1.79)$ & 0.335 \\
\hline $\mathrm{BMI}\left(\mathrm{kg} / \mathrm{m}^{2}\right)$ & $1.02(0.97,1.07)$ & 0.414 & & \\
\hline Systolic BP (mmHg) & $1(0.99,1.01)$ & 0.44 & & \\
\hline Diastolic BP (mmHg) & $0.99(0.98,1.01)$ & 0.439 & & \\
\hline History of Hypertension & $2.08(1.53,2.84)$ & $<0.001$ & $1.9(1.16,3.11)$ & 0.011 \\
\hline History of Type2 DM & $2.12(1.43,3.15)$ & $<0.001$ & $1.59(0.6,4.2)$ & 0.346 \\
\hline History of Dyslipidemia & $1.08(0.63,1.83)$ & 0.786 & & \\
\hline History of smoking (\%) & $1.18(0.82,1.7)$ & 0.373 & & \\
\hline Serum creatinine $(\mathrm{mg} / \mathrm{dL})$ & $2.92(1.35,6.3)$ & 0.007 & & \\
\hline eGFR $\left(\mathrm{ml} / \mathrm{min} / 1.73 \mathrm{~m}^{2}\right)$ & $0.98(0.97,0.99)$ & $<0.001$ & $1(0.99,1.01)$ & 0.817 \\
\hline Aspirin (use) & $3.21(2.17,4.75)$ & $<0.001$ & $2.08(1.2,3.6)$ & 0.009 \\
\hline ACEI/ARBs (use) & $1.93(1.32,2.81)$ & 0.001 & $0.93(0.53,1.61)$ & 0.786 \\
\hline Insulin (use) & $3.42(1.8,6.49)$ & $<0.001$ & $1.13(0.47,2.7)$ & 0.785 \\
\hline Metformin (use) & $1.8(1.15,2.83)$ & 0.01 & $0.47(0.18,1.25)$ & 0.131 \\
\hline
\end{tabular}

Secondary composite outcome includes cardiovascular or renal morbidity and all-cause mortality

$B M I$ Body mass index, BP Blood pressure, DM Diabetes mellitus, eGFR Estimated glomerular filtration rate, ACEI/ARBs Angiotensin-converting enzyme inhibitors/ angiotensin II receptor blockers. All variables are at baseline level

${ }^{a}$ Adjusted by age, gender, type 2 diabetes, hypertension, eGFR, Aspirin, ACEI/ARBs, Insulin and Metformin

Using metformin at baseline showed risk reduction in primary composite outcome, but not secondary composite outcome.

A strength of the present study was the duration of outcome measurement and ability to detect outcome completely because of small community. Several limitations were noted. The relatively small sample size of our cohort study is the main limitation. There was lacking of urine creatinine concentration and 24-h urine albumin, we cannot evaluate urine albumin-to-creatinine ratio (UACR) or albumin excretion rate to avoid the effect of morning urine hyperconcentration after a night fast. This study was conducted in a primary care hospital in rural Thailand where limited oral anti-hypertensive and diabetic medications were available. Drug compliance and duration of drug use were not evaluated in our
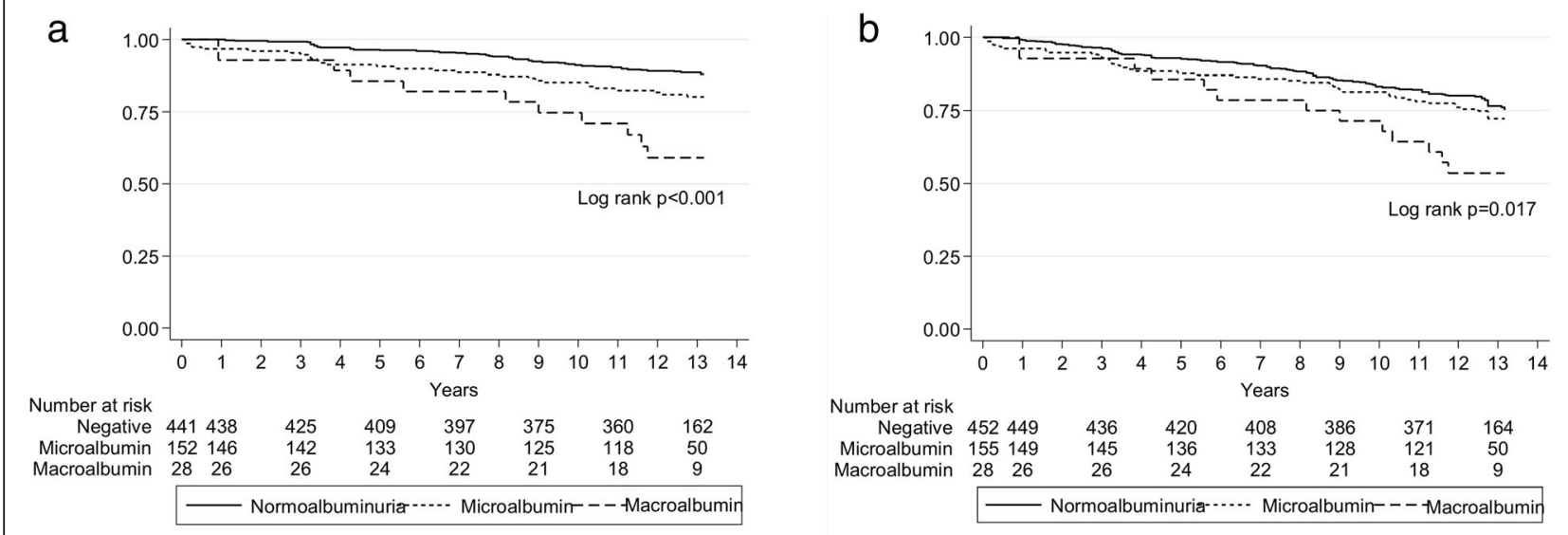

Fig. 2 a Kaplan-Meier curve for primary composite outcome according to urine albumin status (log rank test <0.001). b Kaplan-Meier curve for secondary composite outcome according to urine albumin status (log rank test $=0.017$ ) 
retrospective study. Demographic data of subjects who had missing information of dipstick albumin should be measured and compared with the enrolled subjects. Laboratory variables, especially fasting plasma glucose, hemoglobinA1c and lipid profile, were not collected and measured at baseline. Moreover, laboratory data the end of study should be collected as well to assess the change and to be able to create some variable as the outcomes, for example, rapid renal progression. A systemic bias in laboratory measures in urine dipstick and serum creatinine possibly existed. Finally, the generalizability of our findings might be limited by the selection of middleaged group and subjects living in rural areas of Thailand.

\section{Conclusion}

This study suggests that macroalbuminuria is an independent risk factor for cardiovascular and renal complications, but microalbuminuria is not. Albuminuria from semi-quantitative methods is an important factor predicting cardiovascular and renal risk among subjects in Thai rural population. Our findings support to also incorporating urine albumin dipstick into assessments of cardiovascular risk in the general population.

\section{Acknowledgements}

We thank the community "Baan Nayao" Moo 15 Thakadan, Sanamchaikhet, Chacherngsao, Thailand, staff from Department of Military and Community Medicine, Phramongkutklao College of Medicine, Bangkok, Thailand, Phramongkutklao College of Medicine class $26^{\text {th }}$ and $38^{\text {th }}$ for patient's enrollment and data acquisition. The authors wish to acknowledge Ms. Dollapas Punpanich for statistical analysis.

\section{Authors' contributions}

N.A., K.P., S.S., K.O, KV., TJ, S.J., K.C, V.P., N.H., C.J, T.P., T.T, T.C, P.P. C.W, P.S, N.H., and A.K. collected the data and reviewed the literature. N.A., W.K., R.R., and B.S. provided valuable input in study design, data collection, drafted the article and revised it critically. All authors read and approved the manuscript and met the criteria for authorship.

\section{Funding}

No funding was received.

\section{Availability of data and materials}

The dataset analyzed is available from the corresponding author on reasonable request.

\section{Ethics approval and consent to participate}

The study protocol was approved by the Institutional Review Board of Royal Thai Army Medical Department's committee on human research, approval number is R077h/58, and written informed consent was obtained from all subjects with the WMA Declaration of Helsinki-Ethics principles for medical research involving human subjects.

\section{Consent for publication}

Not applicable.

\section{Competing interests}

The authors declare that no potential conflict of interest exists.

\section{Author details}

'Department of Military and Community Medicine, Phramongkutklao College of Medicine, Bangkok, Thailand. ${ }^{2}$ Department of Medicine, Phramongkutklao College of Medicine, Bangkok, Thailand.
Received: 2 October 2020 Accepted: 16 December 2020

Published online: 08 January 2021

\section{References}

1. Stehouwer CD, Nauta JJ, Zeldenrust GC, Hackeng WH, Donker AJ, den Ottolander GJ. Urinary albumin excretion, cardiovascular disease, and endothelial dysfunction in non-insulin-dependent diabetes mellitus. Lancet. 1992;340(8815):319-23.

2. Hillege HL, Janssen WM, Bak AA, Diercks GF, Grobbee DE, Crijns HJ, et al. Microalbuminuria is common, also in a nondiabetic, nonhypertensive population, and an independent indicator of cardiovascular risk factors and cardiovascular morbidity. J Intern Med. 2001;249(6):519-26.

3. Drury PL, Ting R, Zannino D, Ehnholm C, Flack J, Whiting M, et al. Estimated glomerular filtration rate and albuminuria are independent predictors of cardiovascular events and death in type 2 diabetes mellitus: the Fenofibrate Intervention and Event Lowering in Diabetes (FIELD) study. Diabetologia. 2011;54(1):32-43.

4. Jager A, Kostense PJ, Ruhe HG, Heine RJ, Nijpels G, Dekker JM, et al. Microalbuminuria and peripheral arterial disease are independent predictors of cardiovascular and all-cause mortality, especially among hypertensive subjects: five-year follow-up of the Hoorn study. Arterioscler Thromb Vasc Biol. 1999;19(3):617-24

5. Astor BC, Matsushita K, Gansevoort RT, van der Velde M, Woodward M, Levey AS, et al. Lower estimated glomerular filtration rate and higher albuminuria are associated with mortality and end-stage renal disease. A collaborative meta-analysis of kidney disease population cohorts. Kidney Int. 2011;79(12):1331-40.

6. Sarnak MJ, Astor BC. Implications of proteinuria: CKD progression and cardiovascular outcomes. Adv Chronic Kidney Dis. 2011;18(4):258-66.

7. Agewall S, Wikstrand J, Ljungman S, Fagerberg B. Usefulness of microalbuminuria in predicting cardiovascular mortality in treated hypertensive men with and without diabetes mellitus. Risk Factor Intervention Study Group. Am J Cardiol. 1997;80(2):164-9.

8. Dinneen SF, Gerstein HC. The association of microalbuminuria and mortality in non-insulin-dependent diabetes mellitus. A systematic overview of the literature. Arch Intern Med. 1997;157(13):1413-8.

9. Tonelli M, Muntner P, Lloyd A, Manns BJ, James MT, Klarenbach S, et al. Using proteinuria and estimated glomerular filtration rate to classify risk in patients with chronic kidney disease: a cohort study. Ann Intern Med. 2011; 154(1):12-21.

10. Ninomiya T, Perkovic V, de Galan BE, Zoungas S, Pillai A, Jardine M, et al. Albuminuria and kidney function independently predict cardiovascular and renal outcomes in diabetes. J Am Soc Nephrol. 2009;20(8):1813-21.

11. Targher G, Zoppini G, Chonchol M, Negri C, Stoico V, Perrone F, et al. Glomerular filtration rate, albuminuria and risk of cardiovascular and allcause mortality in type 2 diabetic individuals. Nutr Metab Cardiovasc Dis. 2011;21(4):294-301.

12. Schrader J, Luders S, Kulschewski A, Hammersen F, Zuchner C, Venneklaas $U$, et al. Microalbuminuria and tubular proteinuria as risk predictors of cardiovascular morbidity and mortality in essential hypertension: final results of a prospective long-term study (MARPLE study)*. J Hypertens. 2006;24(3): $541-8$.

13. Ibsen H, Olsen MH, Wachtell K, Borch-Johnsen K, Lindholm LH, Mogensen CE. Reduction in albuminuria translates to reduction in cardiovascular events in hypertensive patients with left ventricular hypertrophy and diabetes. J Nephrol. 2008;21(4):566-9.

14. Hillege HL, Fidler V, Diercks GF, van Gilst WH, de Zeeuw D, van Veldhuisen DJ, et al. Urinary albumin excretion predicts cardiovascular and noncardiovascular mortality in general population. Circulation. 2002;106(14): 1777-82.

15. Konta T, Kudo K, Sato H, Ichikawa K, Ikeda A, Suzuki K, et al. Albuminuria is an independent predictor of all-cause and cardiovascular mortality in the Japanese population: the Takahata study. Clin Exp Nephrol. 2013;17(6): 805-10.

16. Klausen KP, Scharling $H$, Jensen JS. Very low level of microalbuminuria is associated with increased risk of death in subjects with cardiovascular or cerebrovascular diseases. J Intern Med. 2006;260(3):231-7.

17. Grimm RH Jr, Svendsen KH, Kasiske B, Keane WF, Wahi MM. Proteinuria is a risk factor for mortality over 10 years of follow-up. MRFIT Research Group. Multiple Risk Factor Intervention Trial. Kidney Int Suppl. 1997;63:S10-4. 
18. Tanihara S, Hayakawa T, Oki I, Nakamura Y, Sakata K, Okayama A, et al. Proteinuria is a prognostic marker for cardiovascular mortality: NIPPON DATA 80, 1980-1999. J Epidemiol. 2005;15(4):146-53.

19. Culleton BF, Larson MG, Parfrey PS, Kannel WB, Levy D. Proteinuria as a risk factor for cardiovascular disease and mortality in older people: a prospective study. Am J Med. 2000;109(1):1-8

20. Kojima G, Sonoda K, Bell CL, Chen R, Petrovitch H, Abbott RD, et al. Proteinuria in midlife and 39-year total mortality: the Honolulu Heart Program. Ann Epidemiol. 2014;24(5):407-9.

21. Smink PA, Lambers Heerspink HJ, Gansevoort RT, de Jong PE, Hillege $\mathrm{HL}$, Bakker SJ, et al. Albuminuria, estimated GFR, traditional risk factors, and incident cardiovascular disease: the PREVEND (Prevention of Renal and Vascular Endstage Disease) study. Am J Kidney Dis. 2012;60(5):80411.

22. Pesola GR, Argos M, Chen Y, Parvez F, Ahmed A, Hasan R, et al. Dipstick proteinuria as a predictor of all-cause and cardiovascular disease mortality in Bangladesh: a prospective cohort study. Prev Med. 2015;78:72-7.

23. Valmadrid CT, Klein R, Moss SE, Klein BE. The risk of cardiovascular disease mortality associated with microalbuminuria and gross proteinuria in persons with older-onset diabetes mellitus. Arch Intern Med. 2000;160(8):1093-100.

24. Levey AS, Stevens LA, Schmid CH, Zhang YL, Castro AF 3rd, Feldman HI, et al. A new equation to estimate glomerular filtration rate. Ann Intern Med. 2009;150(9):604-12.

25. Berhane AM, Weil EJ, Knowler WC, Nelson RG, Hanson RL. Albuminuria and estimated glomerular filtration rate as predictors of diabetic end-stage renal disease and death. Clin J Am Soc Nephrol. 2011;6(10):2444-51.

26. Araki S, Haneda M, Togawa M, Sugimoto T, Shikano T, Nakagawa T, et al. Microalbuminuria is not associated with cardiovascular death in Japanese NIDDM. Diabetes Res Clin Pract. 1997;35(1):35-40.

27. MacLeod JM, Lutale J, Marshall SM. Albumin excretion and vascular deaths in NIDDM. Diabetologia. 1995;38(5):610-6.

28. Beilin J, Stanton KG, McCann VJ, Knuiman MW, Divitini ML. Microalbuminuria in type 2 diabetes: an independent predictor of cardiovascular mortality. Aust NZ J Med. 1996;26(4):519-25.

29. Uusitupa MI, Niskanen LK, Siitonen O, Voutilainen E, Pyorala K. Ten-year cardiovascular mortality in relation to risk factors and abnormalities in lipoprotein composition in type 2 (non-insulin-dependent) diabetic and non-diabetic subjects. Diabetologia. 1993;36(11):1175-84.

30. Standl E, Schnell O, Balletshofer B, Schleicher E, Muhr D, Ziegler AG, et al. Influence of diabetes mellitus on the heart and macrovascular mortality. Diabetologia. 1997;40(Suppl 2):S125-6.

31. Niskanen LK, Penttila I, Parviainen M, Uusitupa MI. Evolution, risk factors, and prognostic implications of albuminuria in NIDDM. Diabetes Care. 1996;19(5): 486-93.

32. Wirta O, Pasternack A, Mustonen J, Laippala P. Renal and cardiovascular predictors of 9-year total and sudden cardiac mortality in non-insulindependent diabetic subjects. Nephrol Dial Transplant. 1997;12(12):2612-7.

33. Neil A, Hawkins M, Potok M, Thorogood M, Cohen D, Mann J. A prospective population-based study of microalbuminuria as a predictor of mortality in NIDDM. Diabetes Care. 1993;16(7):996-1003

34. Mogensen CE. Microalbuminuria predicts clinical proteinuria and early mortality in maturity-onset diabetes. N Engl J Med. 1984;310(6):356-60.

35. Jarrett RJ, Viberti GC, Argyropoulos A, Hill RD, Mahmud U, Murrells TJ. Microalbuminuria predicts mortality in non-insulin-dependent diabetics. Diabet Med. 1984;1(1):17-9.

36. Schmitz A, Vaeth M. Microalbuminuria: a major risk factor in non-insulindependent diabetes. A 10-year follow-up study of 503 patients. Diabet Med. 1988;5(2):126-34

37. Stiegler H, Standl E, Schulz K, Roth R, Lehmacher W. Morbidity, mortality, and albuminuria in type 2 diabetic patients: a three-year prospective study of a random cohort in general practice. Diabet Med. 1992;9(7):646-53.

38. Mattock MB, Morrish NJ, Viberti G, Keen H, Fitzgerald AP, Jackson G Prospective study of microalbuminuria as predictor of mortality in NIDDM. Diabetes. 1992;41(6):736-41.

39. Damsgaard EM, Froland A, Jorgensen OD, Morgensen CE. Prognostic value of urinary albumin excretion rate and other risk factors in elderly diabetic patients and non-diabetic control subjects surviving the first 5 years after assessment. Diabetologia. 1993;36(10):1030-6.

40. Neil HA, Hawkins MM, Potock MH, Mann Jl. Prognostic value of urinary albumin concentration in diabetic patients surviving the first 5 years after assessment. Diabetologia. 1994;37(12):1287-8.
41. Lunt H, Graham PJ, Jury DR, Lim CW, Crooke MJ, Smith RB, et al. The prognostic significance of urinary albumin in Polynesians with non-insulindependent diabetes. Diabetes Res Clin Pract. 1994;25(3):141-5.

42. Gall MA, Borch-Johnsen K, Hougaard P, Nielsen FS, Parving HH. Albuminuria and poor glycemic control predict mortality in NIDDM. Diabetes. 1995; 44(11):1303-9.

43. Chan JC, Cheung CK, Cheung MY, Swaminathan R, Critchley JA, Cockram CS. Abnormal albuminuria as a predictor of mortality and renal impairment in Chinese patients with NIDDM. Diabetes Care. 1995;18(7):1013-6.

44. Beatty OL, Ritchie CM, Bell PM, Hadden DR, Kennedy L, Atkinson AB Microalbuminuria as identified by a spot morning urine specimen in noninsulin-treated diabetes: an eight-year follow-up study. Diabet Med. 1995; 12(3):261-6.

45. Nelson RG, Sievers ML, Knowler WC, Swinburn BA, Pettitt DJ, Saad MF, et al. Low incidence of fatal coronary heart disease in Pima Indians despite high prevalence of non-insulin-dependent diabetes. Circulation. 1990;81(3):987-95.

46. Nelson RG, Pettitt DJ, Carraher MJ, Baird HR, Knowler WC. Effect of proteinuria on mortality in NIDDM. Diabetes. 1988;37(11):1499-504.

47. Stephenson JM, Kenny S, Stevens LK, Fuller JH, Lee E. Proteinuria and mortality in diabetes: the WHO multinational study of vascular disease in diabetes. Diabet Med. 1995;12(2):149-55.

48. Pell S, D'Alonzo CA. Factors associated with long-term survival of diabetics. JAMA. 1970;214(10):1833-40.

49. Mihara T, Ohashi H, Hirata Y. Mortality and causes of death among Japanese diabetics in the Tokyo area: prospective follow-up study over four years. Tohoku J Exp Med. 1983;141(Suppl):661-4

50. Klein R, Moss SE, Klein BE, DeMets DL. Relation of ocular and systemic factors to survival in diabetes. Arch Intern Med. 1989;149(2):266-72.

51. Sasaki A, Uehara M, Horiuchi N, Hasegawa K, Shimizu T. A 15-year follow-up study of patients with non-insulin-dependent diabetes mellitus (NIDDM) in Osaka, Japan. Factors predictive of the prognosis of diabetic patients. Diabetes Res Clin Pract. 1997;36(1):41-7.

52. Sasaki A. Mortality and causes of death in patients with diabetes mellitus in Japan. Diabetes Res Clin Pract. 1994;24(Suppl):S299-306.

53. Morrish NJ, Stevens LK, Head J, Fuller JH, Jarrett RJ, Keen H. A prospective study of mortality among middle-aged diabetic patients (the London cohort of the WHO multinational study of vascular disease in diabetics) II: associated risk factors. Diabetologia. 1990;33(9):542-8.

54. Hemmelgarn BR, Manns BJ, Lloyd A, James MT, Klarenbach S, Quinn RR, et al. Relation between kidney function, proteinuria, and adverse outcomes. JAMA. 2010;303(5):423-9.

55. Hallan SI, Ritz E, Lydersen S, Romundstad S, Kvenild K, Orth SR. Combining GFR and albuminuria to classify CKD improves prediction of ESRD. J Am Soc Nephrol. 2009;20(5):1069-77.

56. Ishani A, Grandits GA, Grimm RH, Svendsen KH, Collins AJ, Prineas RJ, et al. Association of single measurements of dipstick proteinuria, estimated glomerular filtration rate, and hematocrit with 25-year incidence of endstage renal disease in the multiple risk factor intervention trial. J Am Soc Nephrol. 2006;17(5):1444-52.

57. Halbesma N, Kuiken DS, Brantsma AH, Bakker SJ, Wetzels JF, De Zeeuw D, et al. Macroalbuminuria is a better risk marker than low estimated GFR to identify individuals at risk for accelerated GFR loss in population screening. Am Soc Nephrol. 2006:17(9):2582-90.

58. McEniery CM, Wilkinson IB, Avolio AP. Age, hypertension and arterial function. Clin Exp Pharmacol Physiol. 2007;34(7):665-71.

59. Group DS. Age- and sex-specific prevalences of diabetes and impaired glucose regulation in 13 European cohorts. Diabetes Care. 2003;26(1):61-9.

60. King $H$, Rewers M. Global estimates for prevalence of diabetes mellitus and impaired glucose tolerance in adults. WHO Ad Hoc Diabetes Reporting Group. Diabetes Care. 1993;16(1):157-77.

61. Paneni F, Diaz Canestro C, Libby P, Luscher TF, Camici GG. The aging cardiovascular system: understanding it at the cellular and clinical levels. J Am Coll Cardiol. 2017;69(15):1952-67.

62. North BJ, Sinclair DA. The intersection between aging and cardiovascular disease. Circ Res. 2012;110(8):1097-108.

63. Heidenreich PA, Trogdon JG, Khavjou OA, Butler J, Dracup K, Ezekowitz MD, et al. Forecasting the future of cardiovascular disease in the United States: a policy statement from the American Heart Association. Circulation. 2011; 123(8):933-44

64. Fries JF. Aging, natural death, and the compression of morbidity. N Engl J Med. 1980;303(3):130-5. 
65. Sowers JR. Diabetes mellitus and vascular disease. Hypertension. 2013;61(5): 943-7.

66. Lea JP, Nicholas SB. Diabetes mellitus and hypertension: key risk factors for kidney disease. J Natl Med Assoc. 2002;94(8 Suppl):7S-15S.

67. Patrono C, Bachmann F, Baigent C, Bode C, De Caterina R, Charbonnier B, et al. Expert consensus document on the use of antiplatelet agents. The task force on the use of antiplatelet agents in patients with atherosclerotic cardiovascular disease of the European society of cardiology. Eur Heart J. 2004;25(2):166-81.

68. Herlitz J, Toth PP, Naesdal J. Low-dose aspirin therapy for cardiovascular prevention: quantification and consequences of poor compliance or discontinuation. Am J Cardiovasc Drugs. 2010;10(2):125-41.

69. Lamanna C, Monami M, Marchionni N, Mannucci E. Effect of metformin on cardiovascular events and mortality: a meta-analysis of randomized clinical trials. Diabetes Obes Metab. 2011;13(3):221-8.

\section{Publisher's Note}

Springer Nature remains neutral with regard to jurisdictional claims in published maps and institutional affiliations.

Ready to submit your research? Choose BMC and benefit from:

- fast, convenient online submission

- thorough peer review by experienced researchers in your field

- rapid publication on acceptance

- support for research data, including large and complex data types

- gold Open Access which fosters wider collaboration and increased citations

- maximum visibility for your research: over $100 \mathrm{M}$ website views per year

At BMC, research is always in progress.

Learn more biomedcentral.com/submissions 